\title{
Pathways and Relative Contributions to Arsenic Volatilization from Rice Plants and Paddy Soil
}

\author{
Yan Jia, ${ }^{\dagger, \ddagger}$ Hai Huang, ${ }^{\dagger, \dagger}$ Guo-Xin Sun, ${ }^{\dagger}$ Fang-Jie Zhao, ${ }^{\S}, \|$ and Yong-Guan Zhu ${ }^{\dagger, \perp, *}$ \\ ${ }^{\dagger}$ State Key Lab of Urban and Regional Ecology, Research Center for Eco-Environmental Sciences, Chinese Academy of Sciences, \\ Beijing 100085, China \\ ${ }^{\ddagger}$ Graduate School of the Chinese Academy of Sciences, Beijing 100049, China \\ ${ }^{\S}$ College of Resources and Environmental Science, Nanjing Agricultural University, Nanjing 210095, China \\ "Sustainable Soil and Grassland Systems Department, Rothamsted Research, Harpenden, Hertfordshire AL5 2JQ, United Kingdom \\ ${ }^{\perp}$ Key Lab of Urban Environment and Health, Institute of Urban Environment, Chinese Academy of Sciences, Xiamen 361021, China
}

\section{Supporting Information}

\begin{abstract}
Recent studies have shown that higher plants are unable to methylate arsenic (As), but it is not known whether methylated As species taken up by plants can be volatilized. Rice (Oryza sativa L.) plants were grown axenically or in a nonsterile soil using a two-chamber system. Arsenic transformation and volatilization were investigated. In the axenic system, uptake of As species into rice roots was in the order of arsenate $(\mathrm{As}(\mathrm{V}))>$ monomethylarsonic acid $($ MMAs $(\mathrm{V}))>$ dimethylarsinic acid $(\mathrm{DMAs}(\mathrm{V}))>$ trimethylarsine oxide (TMAs$(\mathrm{V}) \mathrm{O})$, but the order of the root-to-shoot transport index $(\mathrm{T} i)$ was reverse. Also, volatilization of trimethylarsine (TMAs) from rice plants was detected when plants were treated with TMAs(V)O but not with As(V), DMAs(V), or MMAs(V). In the soil culture, As was volatilized mainly from the soil. Small amounts of TMAs were also volatilized from the rice plants, which took up DMAs(V), MMAs(V), and TMAs(V)O from the soil solution. The addition of dried distillers grain (DDG) to the soil enhanced As mobilization into the soil solution, As methylation and volatilization from the soil, as well as uptake of different As species and As volatilization from the rice plants. Results show that rice is able to volatilize TMAs after the uptake of TMAs(V)O but not able to convert inorganic As, MMAs(V) or DMAs(V) into TMAs and that the extent of As volatilization from rice plants was much smaller than that from the flooded soil.
\end{abstract}

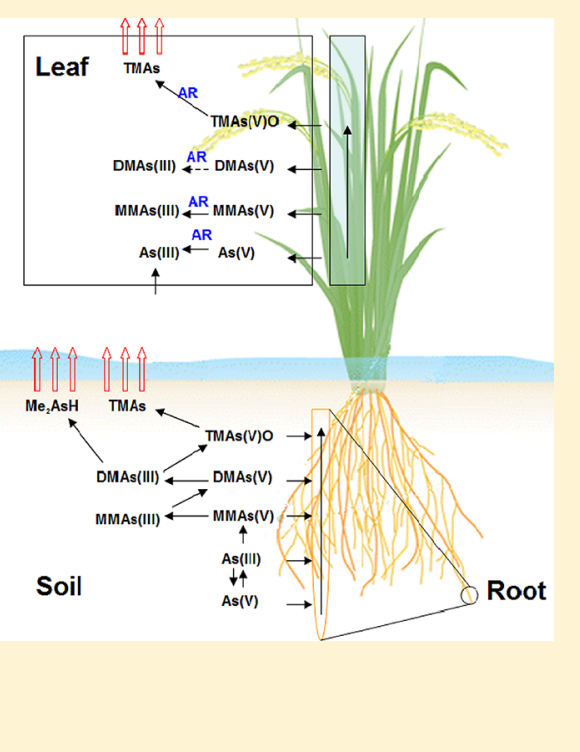

\section{INTRODUCTION}

Arsenic (As) is a class one carcinogen and its contamination in soils can be from natural and/or anthropogenic sources; the latter include mining activities, irrigation of As-contaminated water, use of arsenical herbicides or insecticides, and applications of poultry litter containing As-based intestinal palliatives. ${ }^{1,2}$ In recent decades, millions of people in South and Southeast Asia have suffered from As poisoning from exposure to As contamination in drinking water and rice. ${ }^{2-4}$ Rice is an important source of As exposure because paddy rice is particularly efficient at accumulating As. ${ }^{5}$ The bioavailability of As is greatly elevated when paddy soil is flooded ${ }^{6,7}$ because As is released into the soil solution by As-reducing bacteria or by the reductive dissolution of iron oxyhydroxides mediated by iron-reducing bacteria under anaerobic conditions. ${ }^{8}$ Furthermore, rice takes up arsenite (As(III)) more efficiently than other cereal crops because of the strong silicon uptake pathway, which also allows the uptake of As(III). ${ }^{5,9,10}$

The As species that have been detected in rice grain and plants include As(III), arsenate (As(V)), monomethylarsonic acid (MMAs(V)), monomethylarsonous acid (MMAs(III)), dimethylarsinic acid (DMAs(V)), trimethylarsine oxide (TMAs(V)O), and tetramethylarsonium cation (TETRAs(V)). ${ }^{11-13}$ Although the uptake of methylated As species is slower than that of the inorganic ones, they are more readily transported to rice grains. ${ }^{12,14-16}$ Depending on the geographical location and growth conditions, methylated As in rice grain accounts for from $\sim 10$ to $\sim 90 \%$ of the total As concentration. ${ }^{5}$ Previously, it was thought that plants were able to methylate As. ${ }^{17-19}$ However, recent studies have shown that the methylated As species detected in plants are most likely derived from the growth medium originated from microbial methylation. ${ }^{13,16}$ The pathway of As methylation and biovolatilization in certain bacteria and fungi, proposed by Challenger and co-workers, ${ }^{20-22}$ involves reduction of As(V) to

Received: February 6, 2012

Revised: April 25, 2012

Accepted: June 22, 2012

Published: June 22, 2012 
As(III), followed by oxidative methyl transfer from S-adenosylL-methionine (SAM) to As(III) catalyzed by arsenite $S$ adenosylmethionine methytransferase. Arsenic reduction and methylation can continue for several steps forming methylated As species with 1-4 methyl groups. ${ }^{23}$ A recent study also suggested that methanogenic Archaea are capable of methylating arsenic due to side reactions between central methanogenic cofactors, methylcobalamin. ${ }^{24}$ The volatile As compounds formed by microorganisms are mostly trimethylarsine (TMAs), with small amounts of arsine (AsH3), monomethylarsine (MeAsH2), and dimethylarsine (Me2AsH) also being detected. $^{21}$ After volatilization, TMAs is readily oxidized to TMAs $(\mathrm{V}) \mathrm{O}$ in the atmosphere, which is thought to be almost nontoxic. ${ }^{25}$ Studies on As volatilization from soil have shown that the process is influenced by soil environmental conditions and the chemical forms of As present in the soil. ${ }^{26}$

No As methylation was detected in plants grown under axenic conditions and exposed to inorganic As, indicating that the presence of methylated As species in plants grown in nonsterile medium with inorganic As were of the microbial methylation origin. ${ }^{16}$ It is still not clear whether the UbiE/ Coq5 methyltransferase expressed in rice plants ${ }^{27,28}$ is capable of As methylation. Rice and other plant species are able to reduce $A s(V)$ and $\operatorname{MMAs}(V)$ from the +5 to the +3 valence, ${ }^{16,29-31}$ but the enzyme(s) for the reduction of pentavalent As species are unknown. Though MMAs(III) was detected in a few reports, ${ }^{16,29,31}$ methylated As in the +3 valence are thought to be unstable and can be easily oxidized during the extraction and determination processes, especially for dimethylarsinous acid (DMAs(III)) ${ }^{32}$ this may explain the lack of DMAs(III) detection in higher plants. If TMAs(V)O is taken up by plants, it may be reduced in plants to TMAs, which can then be volatilized. The transgenic rice plants expressing the gene encoding As(III) S-adenosylmethionine methyltransferase ( $\operatorname{ars} M)$ from the soil bacterium Rhodopseudomonas palustris volatilized more As than the untransformed control, ${ }^{33}$ indicating that volatile As species can diffuse out of the rice plants. In the present study, we investigated the potential of As volatilization after the uptake of different methylated As species by rice plants, as well as the relative contributions of soil and plants to the total As volatilization.

\section{MATERIALS AND METHODS}

Axenic Culture Experiment. Conical flasks were filled with $100 \mathrm{~mL}$ half-strength nutrition solution (the full strength nutrition solution contains $5.0 \mathrm{mmol} \mathrm{L} \mathrm{L}^{-1} \mathrm{NH}_{4} \mathrm{NO}_{3}, 2.0 \mathrm{mmol}$ $\mathrm{L}^{-1} \mathrm{~K}_{2} \mathrm{SO}_{4}, 4.0 \mathrm{mmol} \mathrm{L}{ }^{-1} \mathrm{CaCl}_{2}, 1.3 \mathrm{mmol} \mathrm{L}{ }^{-1} \mathrm{KH}_{2} \mathrm{PO}_{4}, 1.5$ $\mathrm{mmol} \mathrm{L}^{-1} \mathrm{MgSO}_{4}, 10 \mu \mathrm{mol} \mathrm{L}{ }^{-1} \mathrm{HBO}_{3}, 5.0 \mu \mathrm{mol} \mathrm{L}{ }^{-1} \mathrm{MnSO}_{4}$, $0.5 \mu \mathrm{mol} \mathrm{L}-1 \mathrm{Na}_{2} \mathrm{MoO}_{4}, 1.0 \mu \mathrm{mol} \mathrm{L}{ }^{-1} \mathrm{ZnSO}_{4}, 1.0 \mu \mathrm{mol} \mathrm{L}{ }^{-1}$ $\mathrm{CuSO}_{4}, 0.2 \mu \mathrm{mol} \mathrm{L}{ }^{-1} \mathrm{CoSO}_{4}, 50 \mu \mathrm{mol} \mathrm{L}{ }^{-1}$ EDTA-2NaFe, $\mathrm{pH}$ 5.5), and $1 \%$ agar. $\operatorname{As}(\mathrm{V}), \operatorname{DMAs}(\mathrm{V}), \operatorname{MMAs}(\mathrm{V})$, and TMAs $(\mathrm{V}) \mathrm{O}$ were added to the medium to a final concentration of $5.0 \mu \mathrm{M}$ for As $(\mathrm{V})$, DMAs $(\mathrm{V})$, and MMAs $(\mathrm{V})$, and 0.2, 1.0, and $5.0 \mu \mathrm{M}$ for TMAs(V)O, respectively. Rice seeds (cv. Jiahua \#1) were sterilized with $75 \%$ ethanol for $5 \mathrm{~min}, 30 \% \mathrm{H}_{2} \mathrm{O}_{2}$ for 5 min, $5 \% \mathrm{NaClO}$ for $10 \mathrm{~min}$, and then washed several times with sterilized water. The seeds were then germinated in the sterilized semisolid nutrient medium. As a control, rice plants were removed from the conical flask - nutrient medium system. The system for trapping volatile As has been described previously $^{34}$ (Figure S1 of the Supporting Information). The whole trapping system was sterilized, and both the inlets and the outlets were fitted with a polytetrafluoroethylene filter $(0.2$ $\mu \mathrm{m}$, Millipore, USA) to prevent microbial contamination. Trapping of volatile As began 7 days after seeding in the medium and lasted for 5 days. Eight seedlings were sown per flask and each treatment was run in four replicates. At the end of the experiment, rice seedlings were washed thoroughly with deionized water, separated into shoots and roots, frozen with liquid $\mathrm{N}_{2}$, and stored at $-80{ }^{\circ} \mathrm{C}$ until As speciation analysis. The transport index $(\mathrm{T} i)$ was calculated to indicate the root to shoot transport efficiency of different As species ( $\mathrm{T} i=\mathrm{As}$ concentration in shoots/As concentration in roots).

Soil Culture Experiment. Rice seeds (cv. Jiahua \#1) were sterilized in $30 \% \mathrm{H}_{2} \mathrm{O}_{2}$ for $15 \mathrm{~min}$, rinsed thoroughly with deionized water, and then germinated in moist perlite. Seedlings were grown in the half-strength nutrient solution for one week before being transplanted into soil pots. The soil used in this experiment was collected from the plow layer (0$20 \mathrm{~cm}$ ) of a mining-contaminated paddy field in Chenzhou city (Hunan province, China). The soil contained $2.98 \mathrm{~g} \mathrm{~kg}^{-1}$ total $\mathrm{N}, 0.67 \mathrm{~g} \mathrm{~kg}^{-1}$ total $\mathrm{P}, 8.7 \mathrm{~g} \mathrm{~kg}^{-1}$ total $\mathrm{K}, 30.7 \mathrm{~g} \mathrm{~kg}^{-1}$ total $\mathrm{Fe}$, $0.60 \mathrm{~g} \mathrm{~kg}^{-1}$ total Mn, $4.52 \mathrm{~g} \mathrm{~kg}^{-1}$ total C, and with a $\mathrm{pH}$ of 6.77 . Arsenic concentration was determined to be $69.6 \mathrm{mg} \mathrm{kg}^{-1}$, which was much higher than the As background value in China $\left(<15 \mathrm{mg} \mathrm{kg}^{-1}\right)$. The soil was air-dried and passed through a 2 $\mathrm{mm}$ mesh sieve. Dried distillers grain (DDG) was the byproduct from brewery using corn and rice, which was shown to be effective in enhancing As methylation when added into the paddy soil. ${ }^{35}$ The As content in DDG was low (0.17 $\left.\mathrm{mg} \mathrm{kg}^{-1}\right)$. Five kilograms of soil were placed in each pot. There were two treatments: control without DDG (-DDG) and addition of DDG at $4 \mathrm{~g} \mathrm{~kg}^{-1}$ soil (+DDG), each with four replicates. To collect volatile As emitted from the soil and the rice plants separately, a two-chamber system (Figure S2 of the Supporting Information) was used. The air pumped into the system was cleaned of any As contamination by passing through an $\mathrm{AgNO}_{3}$ rinsed silica column before entering the soil-plant system. The same setup was used for the control without soil or plants. The trapping of volatile As from the soil and the plants began 2 and 4 weeks after transplantation and continued for 5 and 3 weeks, respectively. Then the rice shoots were cutoff at $3 \mathrm{~cm}$ above the water surface and removed. The upper chamber was wrapped with tinfoil and As volatilization from the soil and the remaining rice roots and shoots was trapped for another 7 weeks during which rice roots might have decomposed partially. The glass tubes used to trap As were replaced weekly.

A similar experiment was conducted with or without DDG addition $\left(4 \mathrm{~g} \mathrm{~kg}^{-1}\right)$ to the soil, rice being grown for the same period of time for the determination of As concentration and its species in rice plants. Before harvest, the shoots were cut at 3 $\mathrm{cm}$ above the water surface and the xylem sap was collected immediately. The incision was rinsed with sterilized deionized water, blotted dry, and covered with a tube containing $0.1 \mathrm{~g}$ sterilized silica wool for $1 \mathrm{~h}$. The As in the tube was rinsed with $100 \mu \mathrm{L} 1 \% \mathrm{HNO}_{3}$ for the analysis of As species. After the collection of xylem sap, roots were removed from the soil and rinsed with deionized water several times. The iron plaque on the root surfaces was extracted with a dithionite-citratebicarbonate (DCB) solution. ${ }^{36,37}$ The concentrations of As, $\mathrm{Fe}, \mathrm{Mn}$, and $\mathrm{P}$ on the iron plaque were determined by ICP-MS (Agilent 7500 series, Agilent Technologies, USA) or ICP-OES (Optima 2000DV, PerkinElmer, USA).

Chemotrapping and Elution of the Volatile As Species. The trapping tubes contained $1 \% \mathrm{AgNO}_{3}$ rinsed 
silica gel and were stuffed with silica wool. ${ }^{34,38}$ Volatile As adsorbed on the silica gel was eluted with $1 \% \mathrm{HNO}_{3}$, and As speciation was determined using HPLC-ICP-MS (Agilent 1200 series and Agilent 7500 series, Agilent Technologies, USA). ${ }^{35}$

Determination of Soil Redox Potential, Dissolved Fe, and As in Pore Water. Redox potential (Eh) of the soil was measured with a platinum electrode (Aidahengsheng Technology, China) at a depth of $8 \mathrm{~cm}$ in the soil, using an $\mathrm{Ag} / \mathrm{AgCl}$ electrode (Aidahengsheng Technology, China) as the reference. The soil solution was extracted weekly through a rhizosampler (Rhizon Soil Moisture Samplers; Rhizosphere Research Products, The Netherlands) inserted into the soil, and acidified with $1 \% \mathrm{HNO}_{3}$. Dissolved $\mathrm{Fe}, \mathrm{Mn}, \mathrm{P}$, and As in the soil solution were determined by ICP-OES or ICP-MS.

Determination of As Species and Total As Concentrations in Plants. For the determination of As speciation, fresh roots and shoots from the axenic culture experiment were grounded in liquid $\mathrm{N}_{2}$, and extracted with $5 \mathrm{~mL} 1 \% \mathrm{HNO}_{3}$. The roots (after DCB extraction) and shoots from the soil culture were freeze-dried and ground to powder in liquid $\mathrm{N}_{2}$. Two hundred milligrams of powder was weighed into a $50 \mathrm{ml}$ tube, to which $5 \mathrm{~mL} 1 \% \mathrm{HNO}_{3}$ was added. The extraction took place in a microwave digestion system (MARS, CEM Microwave Technology, USA). ${ }^{39}$ The speciation of As in roots and shoots was determined using HPLC-ICP-MS. Arsenic species (As(III), As(V), DMAs(V), MMAs(V)) were separated by an anion-exchange column (PRP X-100, Hamilton Company, USA) with the mobile phase of $7.0 \mathrm{mM}\left(\mathrm{NH}_{4}\right)_{2} \mathrm{HPO}_{4}$ and 7.0 $\mathrm{mM} \mathrm{NH}_{4} \mathrm{NO}_{3}$ ( $\mathrm{pH}$ 6.2). For the determination of TMAs(V)O, As(III), which coeluted with TMAs(V)O, was oxidized to As $(V)$ with $\mathrm{H}_{2} \mathrm{O}_{2}$ in an $1: 1$ sample $/ \mathrm{H}_{2} \mathrm{O}_{2}$ mixture, which was stored at $4{ }^{\circ} \mathrm{C}$ for 1 week. The As species in the soil solution and volatile As species were also determined using HPLCICP-MS.

To determine the total As concentrations in shoots and roots, freeze-dried milled samples $(0.1-0.2 \mathrm{~g})$ from the soil culture experiment were digested with $2.5 \mathrm{~mL}$ of nitric acid using a microwave digestion system, and determined by ICPMS.

\section{RESULTS}

Arsenic Uptake and Translocation in Rice Seedlings Grown Axenically. Uptake of As into rice roots varied between As species (Table 1). As (V) was taken up the most by rice roots, followed by MMAs (V), DMAs $(\mathrm{V})$, and TMAs $(\mathrm{V}) \mathrm{O}$ with a 21.3 fold difference between $\mathrm{As}(\mathrm{V})$ and TMAs(V)O (Table 1). In the DMAs(V) and TMAs(V)O treatments, the only As species detected in the rice plants was that added to the

Table 1. Arsenic Concentrations in Shoots and Roots, and the Calculated Transport Index (Ti) of Rice Seedlings Grown on the Sterilized Agar Nutrition Medium Amended with $5 \mu \mathrm{M}$ As(V), MMAs(V), DMAs(V), or TMAs $(\mathrm{V}) \mathrm{O}^{a}$

$\begin{array}{lccc} & \begin{array}{c}\text { shoot As }\left(\mathrm{mg} \mathrm{kg}^{-1}\right. \\ \mathrm{FW})\end{array} & \begin{array}{c}\text { root As }\left(\mathrm{mg} \mathrm{kg}^{-1}\right. \\ \mathrm{FW})\end{array} & \begin{array}{c}\text { As transport index } \\ (\mathrm{T} i)\end{array} \\ \mathrm{As}(\mathrm{V}) & 0.49 \pm 0.06 & 11.76 \pm 1.55 & 0.041 \pm 0.005 \\ \mathrm{MMAs}(\mathrm{V}) & 0.26 \pm 0.05 & 10.34 \pm 1.25 & 0.025 \pm 0.004 \\ \mathrm{DMAs}(\mathrm{V}) & 0.11 \pm 0.02 & 0.60 \pm 0.06 & 0.190 \pm 0.021 \\ \text { TMAs(V)O } & 0.15 \pm 0.03 & 0.55 \pm 0.06 & 0.267 \pm 0.052\end{array}$

${ }^{a}$ Data are means \pm SE $(n=4)$. growth medium. In the MMAs $(\mathrm{V})$ treatment, $\operatorname{MMAs}(\mathrm{V})$ and small amounts of As(III) were detected in the plants (Figure S3 of the Supporting Information). As(III) was the predominant species in the rice plants exposed to As $(\mathrm{V})$, with no methylated As being detected (Figure S3 of the Supporting Information). Opposite to the root uptake, the translocation of TMAs $(\mathrm{V}) \mathrm{O}$ from roots to shoots was the highest, followed by DMAs $(\mathrm{V})$, MMAs(V), and As(V). The Ti of TMAs(V)O was 6.5 times higher than that of As(V).

Arsenic Volatilization from Rice Seedlings Grown Axenically. Volatile As, in the form of TMAs, was observed only in the TMAs $(\mathrm{V}) \mathrm{O}$ treatment; no volatile As was detected in the $\operatorname{As}(\mathrm{V}), \operatorname{MMAs}(\mathrm{V})$, or DMAs $(\mathrm{V})$ treatments (Figure S4 of the Supporting Information). No volatile As was detected in the controls (no plants) with the addition of As(V), MMAs(V), DMAs $(V)$, or TMAs $(\mathrm{V}) \mathrm{O}$ to the axenic culture medium. The quantity of volatile As from the rice plants increased with the increasing concentration of TMAs $(\mathrm{V}) \mathrm{O}$ added to the medium. The largest amount of volatile As was $580 \mathrm{ng}$ during the 5 day trapping period in the presence of $5 \mu \mathrm{M}$ TMAs(V)O (Figure 1)

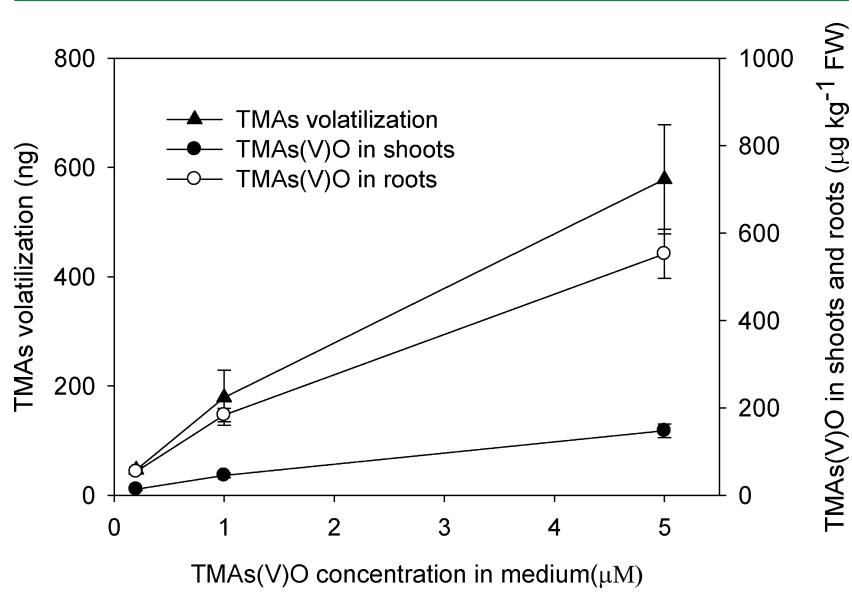

Figure 1. Volatilized TMAs from rice plants and TMAs(V)O concentrations in roots and shoots of rice grown on the sterilized agar nutrition medium added with $0.2,1.0$, and $5.0 \mu \mathrm{M}$ TMAs(V)O. Data are means $\pm \operatorname{SE}(n=4)$.

accounting for $137.6 \%$ of the total As in the rice plants and $0.15 \%$ of the As added to the medium. The volatilization of As was positively related to the TMAs $(\mathrm{V}) \mathrm{O}$ concentration in the shoots and roots of the rice plants exposed to different concentrations of TMAs(V)O (Figure 1).

Dynamic As Transformation in the Soil Solution. In the soil culture experiment, seven As species were detected in the soil solution including As(III), As(V), DMAs(V), MMAs(V), TMAs(V)O, and two unidentified As species (Figure 2 and Figure S5 of the Supporting Information). We speculated that the unknown peak 1 was TETRAs(V) compared with the chromatograms reported in the literature. ${ }^{11}$ This small peak was detected only in the +DDG treatment, whereas the other 6 As species were observed in both treatments. The second unknown As peak was not detected in the samples collected at the beginning of the experiment but increased greatly with time under the anaerobic conditions. When the soil solution samples were oxidized with $\mathrm{H}_{2} \mathrm{O}_{2}$, this peak remained stable (Figure S5 of the Supporting Information), suggesting that it 

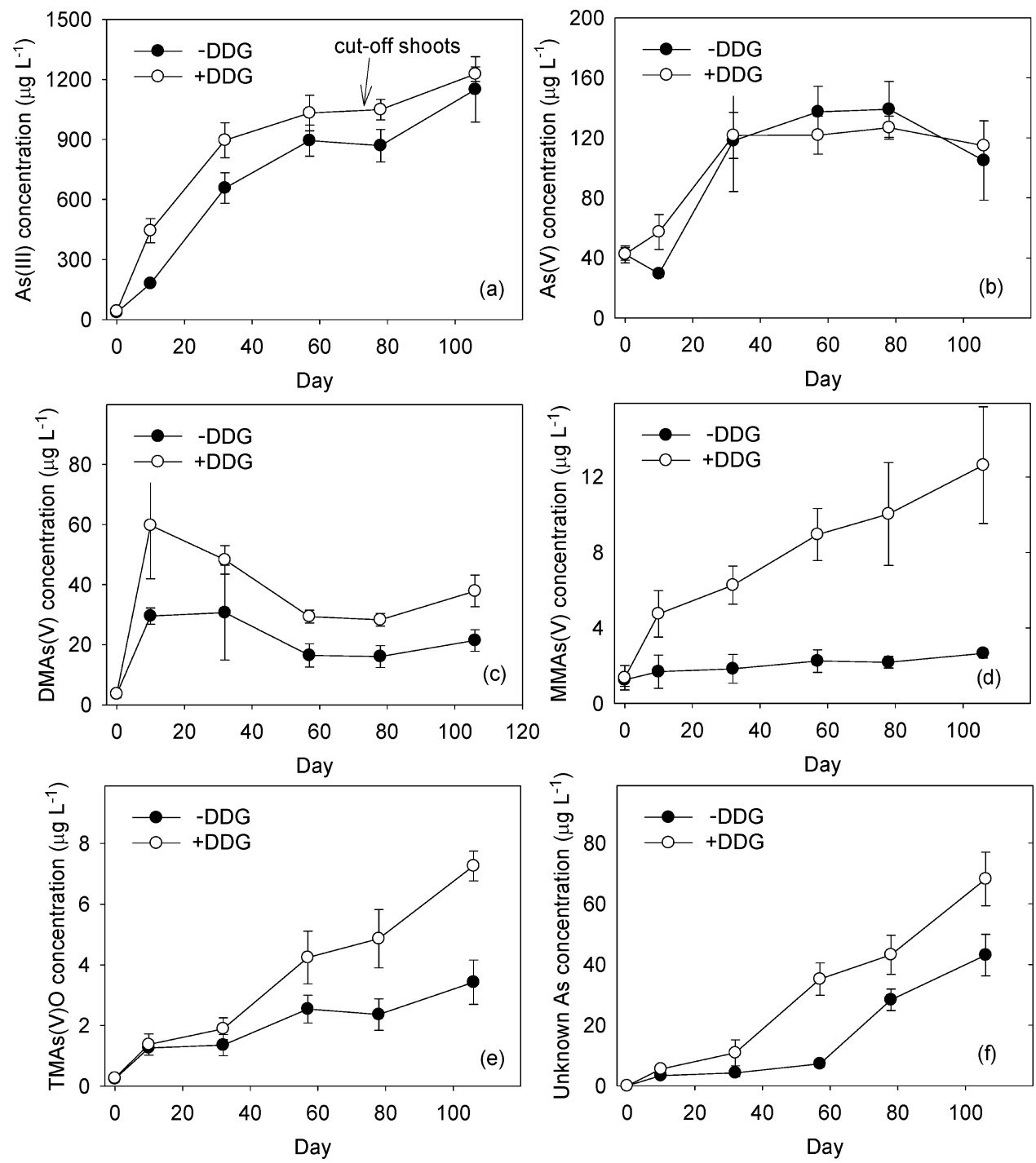

Figure 2. Concentrations of different As species ((a) As(III), (b) As(V), (c) DMAs(V), (d) MMAs(V), (e) TMAs(V)O, (f) unknown As) in the soil solution during the growth of rice plants and after cutoff in the rice plants of the two treatments with or without DDG addition. -DDG, without DDG addition in the soil; +DDG, with DDG addition in the soil. Data are means \pm SE $(n=4)$.

Table 2. Arsenic Species and Total As Concentrations in Xylem Sap, Roots, and Shoots of Rice Plants ${ }^{a}$

\begin{tabular}{|c|c|c|c|c|c|c|}
\hline & \multicolumn{2}{|c|}{ Xylem sap As $\left(\mu \mathrm{g} \mathrm{mL}^{-1}\right)$} & \multicolumn{2}{|c|}{ Shoot As ( $\left.\mathrm{mg} \mathrm{kg}^{-1} \mathrm{DW}\right)$} & \multicolumn{2}{|c|}{ Root As (mg kg-1 DW) } \\
\hline & $-\mathrm{DDG}$ & + DDG & $-\mathrm{DDG}$ & + +DDG & $-\mathrm{DDG}$ & + DDG \\
\hline As(III) & $6.08 \pm 1.58$ & $10.92 \pm 1.01^{b}$ & $4.39 \pm 0.65$ & $8.72 \pm 1.23^{b}$ & $83.9 \pm 10.2$ & $175.1 \pm 20.5^{b}$ \\
\hline $\operatorname{As}(V)$ & $3.08 \pm 0.76$ & $5.49 \pm 0.77^{b}$ & $1.29 \pm 0.08$ & $3.38 \pm 0.71^{b}$ & $105.2 \pm 20.1$ & $231.9 \pm 38.6^{b}$ \\
\hline $\operatorname{DMAs}(\mathrm{V})$ & $0.72 \pm 0.20$ & $6.06 \pm 1.27^{b}$ & $0.42 \pm 0.04$ & $1.68 \pm 0.12^{b}$ & $2.6 \pm 0.54$ & $6.9 \pm 2.6^{b}$ \\
\hline $\operatorname{MMAs}(\mathrm{V})$ & n.d. & n.d. & $0.08 \pm 0.01$ & $0.24 \pm 0.03^{b}$ & $0.22 \pm 0.05$ & $0.93 \pm 0.12^{b}$ \\
\hline TMAs(V)O & n.d. & $0.22 \pm 0.09^{b}$ & n.d. & $0.02 \pm 0.01^{b}$ & n.d. & $0.08 \pm 0.02^{b}$ \\
\hline sum As & $9.88 \pm 1.53$ & $22.47 \pm 1.35^{b}$ & $6.18 \pm 0.55$ & $14.22 \pm 1.34^{b}$ & $119.9 \pm 21.3$ & $414.91 \pm 35.2^{b}$ \\
\hline total As & $11.2 \pm 2.05$ & $25.32 \pm 2.26^{b}$ & $6.02 \pm 0.60$ & $13.14 \pm 1.03^{b}$ & $202.8 \pm 19.5$ & $450.6 \pm 46.2^{b}$ \\
\hline
\end{tabular}

${ }^{a}$ Sum As: sum of the five As species. -DDG: without DDG addition in the soil; +DDG: with DDG addition in the soil. ${ }^{b}$ Significant differences $(p<$ $0.05)$ between $-\mathrm{DDG}$ and $+\mathrm{DDG}$ treatments in shoots and roots, respectively. Data are means $\pm \mathrm{SE}(n=4)$. n.d.: not detected.

was not MMAs(III), DMAs(III) or - SH binding As, because these species were unstable under oxidizing conditions.

The release of As into the soil solution during the flooding period was closely related to the decreasing Eh (exponential decay, $r=0.957, p<0.001)$ and linearly related to the concentration of dissolved Fe $(r=0.763, p<0.001)$ in the $-\mathrm{DDG}$ and +DDG treatments (Figure S6 of the Supporting
Information). As(III) was the predominant As species in the soil solution followed by $\mathrm{As}(\mathrm{V})$ and the methylated As species after a period of flooding (Figure 2, Figure S5 of the Supporting Information). DMAs(V) was the predominant organic As species (Figure 2, Figure S5 of the Supporting Information), whereas the concentrations of MMAs(V) and TMAs(V)O were small. All As species increased during the experimental period, 
except DMAs(V) which appeared to peak after only 10 days of incubation. The addition of DDG significantly increased the concentrations of both inorganic and organic As in the soil solution $(p<0.05)$ (Figure 2).

Arsenic Uptake and Translocation in Rice Plants Grown in Soil. The As species in the xylem sap of the rice plants were As(III), As(V), and DMAs(V) in the -DDG treatment (Table 2). A very small amount of TMAs $(\mathrm{V}) \mathrm{O}$ was detected in the xylem sap from the +DDG treatment. The concentrations of the As species were significantly increased, especially for DMAs(V) (by 8.4 folds) by the addition of DDG. Similarly, the concentrations of all As species, especially methylated As, in rice shoots and roots were greatly increased in the +DDG treatment compared with the -DDG treatment. The total inorganic As species in +DDG increased by $79 \%$, $113 \%$, and $115 \%$ in the xylem sap, shoots, and roots compared to the -DDG treatment, respectively; the corresponding increases in the methylated As species were $772 \%, 288 \%$, and $180 \%$, respectively.

Arsenic Volatilization from Plants and Soil in the TwoChamber System. Arsenic volatilization was detected from both the soil and the rice plants although the amount emitted from the latter was much smaller (Figure 3). Arsenic

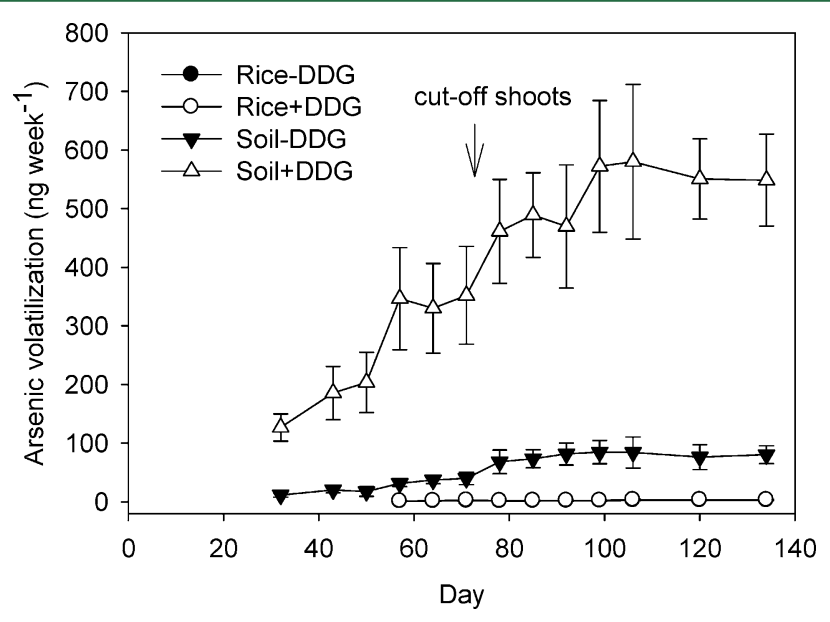

Figure 3. Arsenic volatilization from rice plants and from soil during the growth of rice and after the cutoff of rice shoots in the two treatments with or without DDG addition. Rice - DDG, As volatilized from rice plants without DDG addition in the soil; rice + DDG, As volatilized from rice plants with DDG addition in the soil; soil DDG, As volatilized from soil without DDG addition in the soil; soil + DDG, As volatile from soil with DDG addition in the soil. Data are means \pm SE $(n=4)$. The data from the treatments of Rice - DDG and Rice + DDG were not able to be separated from the figure.

volatilization from the rice plants accounted for only 0.4$3.2 \%$ of the total As volatilized from the whole system. The amount of As volatilized from the soil and rice plants increased steadily after the flooding of the soil. After the rice shoots were cut off, As volatilization from the soil containing rice stubbles decreased at first, followed by small increases. The As species volatilized from the paddy soil were mainly TMAs, followed by small amounts of $\mathrm{Me}_{2} \mathrm{AsH}$ and $\mathrm{AsH}_{3}$, whereas only TMAs was volatilized from rice plants (Figure 4). The amount of As volatilization from both soil and plants were much higher in the +DDG treatment than that in the -DDG treatment.

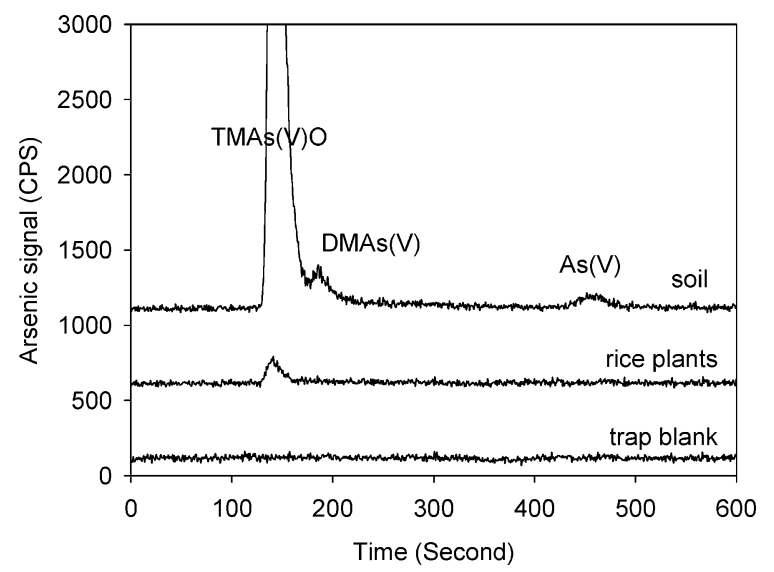

Figure 4. Chromatogram of As species volatilized from rice plants and soil. Volatiles $\mathrm{AsH}_{3}, \mathrm{Me}_{2} \mathrm{AsH}$, and TMAs are quantitatively converted to their oxy-anions equivalent during trapping/digesting process, respectively $\mathrm{As}(\mathrm{V})$, DMAs $(\mathrm{V})$, and TMAs $(\mathrm{V}) \mathrm{O}$. The peaks of $\operatorname{TMAs}(\mathrm{V}) \mathrm{O}, \operatorname{DMAs}(\mathrm{V})$, and $\mathrm{As}(\mathrm{V})$ represents the trapped volatile As species of TMAs, $\mathrm{Me}_{2} \mathrm{AsH}$, and $\mathrm{AsH}_{3}$, respectively.

\section{DISCUSSION}

Whether rice plants are able to methylate and volatilize As is important for understanding the As biogeochemical cycle in paddy systems in general and As accumulation in rice plants in particular. The results from the axenic culture experiment demonstrate that rice was able to volatilize As in the form of TMAs only when TMAs(V)O was added to the medium. It has been shown that plants including rice are able to reduce MMAs(V) to MMAs(III), ${ }^{16,29,31}$ although the enzyme(s) responsible for this reduction remain unknown. It is probable that rice can also reduce $\mathrm{TMAs}(\mathrm{V}) \mathrm{O}$ to volatile TMAs. MMAs(III) was not detected in our experiment, as has been shown before, ${ }^{31}$ possibly because the mobile phase used was not able to resolve the possible coelution of DMAs(V) and MMAs(III), as found by Li et al. ${ }^{31}$ and Ye et al. ${ }^{29}$

Despite the ability of rice plants to reduce TMAs $(\mathrm{V}) \mathrm{O}$ and to volatilize TMAs, it is clear that rice is not able to methylate As. Our results are consistent with those of Lomax et al. ${ }^{16}$ that no methylated As species was detected in roots and shoots in the treatment with $\mathrm{As}(\mathrm{V})$ under axenic culture (Figure S3 of the Supporting Information), and there was no further methylation in planta of either MMAs(V) or DMAs(V). This conclusion is also supported by the lack of TMAs volatilization from plants exposed to As(V), DMAs(V), or MMAs(V). The previously detected methylated As species in plants grown in the inorganic As-containing medium (40-42) were most likely attributed to the As methylation mediated by microbes because these experiments were not conducted under axenic conditions. Furthermore, there was relatively little demethylation of methylated As species taken up by rice plants during the 12 day experiment.

Similar to previous studies, ${ }^{15,43,44}$ we found that MMAs(V) and DMAs(V) had a much higher Ti than inorganic As. Uptake and translocation of TMAs(V)O in plants were investigated for the first time in our study. The results show that the root uptake decreased, whereas $\mathrm{T} i$ increased with the degree of As methylation (Table 1). The highly efficient translocation of methylated As species thus explains the higher percentages of these As species in rice grains than in the shoots and roots. ${ }^{12-14}$ In the nonsterile soil experiment, methylated As species including $\operatorname{MMAs}(\mathrm{V})$, DMAs(V), and TMAs(V)O were 
produced in the soil solution after flooding. These species were also taken up by the rice plants. Arsenic volatilization was detected from both the soil and the plants, although, the latter was only a small fraction of the former. Further, the volatile As emitted by the rice plants was TMAs only. When the results from both the axenic and the soil experiments are considered together, it can be concluded that the volatile As from the rice plants originated from the uptake of TMAs $(\mathrm{V}) \mathrm{O}$ produced by soil microbes, not from the in planta methylation of inorganic As or further methylation of MMAs(V) and DMAs(V).

Our results indicate that As volatilization from flooded paddy soil was quantitatively far more important than that from rice plants. TMAs is the most abundant As species volatilized from the soil environment with small amounts of $\mathrm{Me}_{2} \mathrm{AsH}$ and $\mathrm{AsH}_{3}$ also being detected (Figure 4 and refs 45 and 46). Some bacteria can volatilize $\mathrm{Me}_{2} \mathrm{AsH}$ when grown in the Ascontaining medium, but there is no general consensus as to the mechanism of the $\mathrm{Me}_{2} \mathrm{AsH}$ formation. ${ }^{21} \mathrm{MMAs}(\mathrm{V})$ and DMAs(V) were not volatilized in the form of $\mathrm{MeAsH}_{2}$ and $\mathrm{Me}_{2} \mathrm{AsH}$ from the rice plants in the axenic culture (Figure S4 of the Supporting Information) implying that these volatile species cannot be produced from MMAs $(\mathrm{V})$ or DMAs $(\mathrm{V})$ by rice plants.

Consistent with previous reports, ${ }^{35}$ additions of organic matter such as DDG greatly promoted the release of As into the soil solution, accompanied by an enhanced reductive dissolution of iron-oxides (Figure S6 of the Supporting Information). DDG addition resulted in lower $\mathrm{Fe}$ and $\mathrm{Mn}$ contents on the root surface (Figure S7 of the Supporting Information), which might lead to more As uptake in the +DDG treatment due to the lower binding ability to As on the root surface. ${ }^{37}$ Arsenic methylation by the microbes in the soil was increased by the addition of DDG, which resulted in a greater relative increase in the methylated As species than the inorganic As species in the soil solution. The volatilization of methylated As from both the rice plants and the soil were increased by DDG addition. There was also evidence that soils spiked with organic matters, such as cow dung and rice straw, increased the emission of volatile As into the atmosphere. ${ }^{38,45}$ It was noted that As volatilization from the soil was increased after rice shoots were cut possibly because of the decomposition of the roots resulting in similar effects to amendments of organic matter to the soil. ${ }^{38,45}$

In conclusion, TMAs was volatilized from rice plants grown in sterilized medium amended with $\mathrm{TMAs}(\mathrm{V}) \mathrm{O}$ and in a nonsterile As contaminated soil, but not when the sterilized medium was amended with $\operatorname{MMAs}(\mathrm{V}), \operatorname{DMAs}(\mathrm{V})$, or As(V), indicating a lack of the As methylation ability in rice plants. The origin of TMAs emitted by the soil-grown rice was TMAs(V)O produced by soil microbes. The uptake and volatilization of As by rice plants was enhanced by the addition of DDG to soil due to enhanced As mobilization and methylation in the soil solution. This study provides an insight into As volatilization in rice plants, its extent being much smaller than that from the flooded soil. As volatilization from rice plants helps to decrease the As accumulation in rice, although the effect is limited and only occurred when TMAs $(\mathrm{V}) \mathrm{O}$ is taken up by the plants. Further work will focus on the strategies of enhancing the As volatilization from plants and their possible use in reducing As accumulation in rice and in enhancing phytoremediation.

\section{ASSOCIATED CONTENT}

\section{Supporting Information}

Information of the used conical flask system; two-chamber system; arsenic species in shoots of rice plants grown on the axenic medium; chromatogram of the volatile As from the conical system; chromatogram of the As speciation in the soil solution; As and Fe concentrations in the soil solution, Eh of the Soil, the relationship between $\mathrm{Eh}$ and Fe dissolution, the relationship between Eh and As dissolution, and the relationship between Fe concentration and As concentration; element compositions of the iron plaque on the root surface. This material is available free of charge via the Internet at http:// pubs.acs.org.

\section{AUTHOR INFORMATION}

\section{Corresponding Author}

*Phone: 86-592-6190997, fax: 86-592-6190997, e-mail: ygzhu@rcees.ac.cn.

\section{Notes}

The authors declare no competing financial interest.

\section{ACKNOWLEDGMENTS}

This work is financially supported by Natural Science Foundation of China (41090284 and 41090282), the Chinese Academy of Sciences (KZCX2-YW-Q02-06), and the CAS/ SAFEA International Partnetship Program for Creative Research Team (KZCX2-Yw-T08). The authors would like to thank Dr. Adrien Mestrot for constructive suggestions on the experiments and Dr. Dan $\mathrm{Li}$ for suggestion in manuscript writing.

\section{REFERENCES}

(1) Oremland, R. S.; Stolz, J. F. The ecology of arsenic. Science 2003, 300 (5621), 939-944.

(2) Zhu, Y. G.; Williams, P. N.; Meharg, A. A. Exposure to inorganic arsenic from rice: A global health issue? Environ. Pollut. 2008, 154 (2), 169-171.

(3) Mondal, D.; Polya, D. A. Rice is a major exposure route for arsenic in Chakdaha block, Nadia district, West Bengal, India: A probabilistic risk assessment. Appl. Geochem. 2008, 23 (11), 29872998.

(4) Neumann, R. B.; St. Vincent, A. P.; Roberts, L. C.; Badruzzaman, A. B. M.; Ali, M. A.; Harvey, C. F. Rice field geochemistry and hydrology: An explanation for why groundwater irrigated fields in Bangladesh are net sinks of arsenic from groundwater. Environ. Sci. Technol. 2011, 45 (6), 2072-2078.

(5) Zhao, F. J.; McGrath, S. P.; Meharg, A. A. Arsenic as a food chain contaminant: Mechanisms of plant uptake and metabolism and mitigation strategies. Annu. Rev. Plant Biol. 2010, 61, 535-559.

(6) Xu, X. Y.; McGrath, S. P.; Meharg, A. A.; Zhao, F. J. Growing rice aerobically markedly decreases arsenic accumulation. Environ. Sci. Technol. 2008, 42 (15), 5574-5579.

(7) Stroud, J. L.; Khan, M. A.; Norton, G. J.; Islam, M. R.; Dasgupta, T.; Zhu, Y. G.; Price, A. H.; Meharg, A. A.; McGrath, S. P.; Zhao, F. J. Assessing the labile arsenic pool in contaminated paddy soils by isotopic dilution techniques and simple extractions. Environ. Sci. Technol. 2011, 45 (10), 4262-4269.

(8) Weber, F. A.; Hofacker, A. F.; Voegelin, A.; Kretzschmar, R. Temperature dependence and coupling of iron and arsenic reduction and release during flooding of a contaminated soil. Environ. Sci. Technol. 2009, 44 (1), 116-122.

(9) Su, Y. H.; McGrath, S. P.; Zhao, F. J. Rice is more efficient in arsenite uptake and translocation than wheat and barley. Plant Soil 2010, 328 (1-2), 27-34. 
(10) Ma, J. F.; Yamaji, N.; Mitani, N.; Xu, X. Y; Su, Y. H.; McGrath, S. P.; Zhao, F. J. Transporters of arsenite in rice and their role in arsenic accumulation in rice grain. Proc. Natl. Acad. Sci. U.S.A. 2008, 105, 9931-9935.

(11) Hansen, H. R.; Raab, A.; Price, A. H.; Duan, G. L.; Zhu, Y. G.; Norton, G. J.; Feldmann, J.; Meharg, A. A. Identification of tetramethylarsonium in rice grains with elevated arsenic content. $J$. Environ. Monit. 2011, 13, 32-34.

(12) Zheng, M. Z.; Cai, C.; Hu, Y.; Sun, G. X.; Williams, P. N.; Cui, H. J.; Duan, G. L.; Zhao, F. J.; Zhu, Y. G. Spatial distribution of arsenic and temporal variation of its concentration in rice. New Phytol. 2011, 189, 200-209.

(13) Arao, T.; Kawasaki, A.; Baba, K.; Matsumoto, S. Effects of arsenic compound amendment on arsenic speciation in rice grain. Environ. Sci. Technol. 2011, 45 (4), 1291-1297.

(14) Carey, A. M.; Norton, G. J.; Deacon, C.; Scheckel, K. G.; Lombi, E.; Punshon, T.; Guerinot, M. L.; Lanzirotti, A.; Newville, M.; Choi, Y. Phloem transport of arsenic species from flag leaf to grain during grain filling. New Phytol. 2011, 192, 87-98.

(15) Abedin, M. J.; Feldmann, J.; Meharg, A. A. Uptake kinetics of arsenic species in rice plants. Plant Physiol. 2002, 128 (3), 1120-1128.

(16) Lomax, C.; Liu, W. J.; Wu, L.; Xue, K.; Xiong, J.; Zhou, J.; McGrath, S. P.; Meharg, A. A.; Miller, A. J.; Zhao, F. J. Methylated arsenic species in plants originate from soil microorganisms. New Phytol. 2011, 193 (3), 665-672.

(17) Nissen, P.; Benson, A. A. Arsenic metabolism in freshwater and terrestrial plants. Physiol. Plant. 1982, 54, 446-450.

(18) Wu, J. H.; Zhang, R.; Lilley, R. M. Methylation of arsenic in vitro by cell extracts from bentgrass (Agrostis tenuis): Effect of acute exposure of plants to arsenate. Funct. Plant Biol. 2002, 29, 73-80.

(19) Zavala, Y. J.; Gerads, R.; Gürleyük, H.; Duxbury, J. M. Arsenic in rice: II. Arsenic speciation in USA grain and implications for human health. Environ. Sci. Technol. 2008, 42, 3861-3866.

(20) Challenger, F. Biological methylation. Chem. Rev. 1945, 36 (3), 315-361.

(21) Bentley, R.; Chasteen, T. G. Microbial methylation of metalloids: arsenic, antimony, and bismuth. Microbiol. Mol. Biol. Rev. 2002, 66 (2), 250-271.

(22) Qin, J.; Rosen, B. P.; Zhang, Y.; Wang, G. J.; Franke, S.; Rensing, C. Arsenic detoxification and evolution of trimethylarsine gas by a microbial arsenite $S$-adenosylmethionine methyltransferase. Proc. Natl. Acad. Sci. U.S.A. 2006, 103 (7), 2075-2080.

(23) Hayakawa, T.; Kobayashi, Y.; Cui, X.; Hirano, S. A new metabolic pathway of arsenite: arsenic-glutathione complexes are substrates for human arsenic methyltransferase Cyt19. Arch. Toxicol. 2005, 79, 183-191.

(24) Wuerful, O.; Thomas, F.; Schulte, M. S.; Hensel, R.; Diaz-Bone, R. A. Mechanism of muti-metal(loid) methylation and hydrite generation by methylcobalamin and cob(1)alamin: a side reaction of methanogenesis. Appl. Organometal. Chem. 2012, 26, 94-101.

(25) Bhattacharya, P.; Welch, A.; Stollenwerk, K.; McLaughlin, M.; Bundschuh, J.; Panaullah, G. Arsenic in the environment: biology and chemistry. Sci. Total Environ. 2007, 379 (2-3), 109-120.

(26) Huang, J. H.; Hu, K. N.; Decker, B. Organic arsenic in the soil environment: speciation, occurrence, transformation, and adsorption behavior. Water Air Soil Pollut. 2011, 219, 1-15.

(27) Norton, G. J.; Lou-Hing, D. E.; Meharg, A. A.; Price, A. H. Rice-arsenate interactions in hydroponics: Whole genome transcriptional analysis. J. Exp. Bot. 2008, 59 (8), 2267-2276.

(28) Norton, G. J.; Islam, M. R.; Deacon, C. M.; Zhao, F. J.; Stroud, J. L.; McGrath, S. P.; Islam, S.; Jahiruddin, M.; Feldmann, J.; Price, A. H. Identification of low inorganic and total grain arsenic rice cultivars from Bangladesh. Environ. Sci. Technol. 2009, 43 (15), 6070-6075.

(29) Ye, W. L.; Wood, B. A.; Stroud, J. L.; Andralojc, P. J.; Raab, A.; McGrath, S. P.; Feldmann, J.; Zhao, F. J. Arsenic speciation in phloem and xylem exudates of castor bean. Plant Physiol. 2010, 154 (3), 15051513.
(30) Xu, X. Y.; McGrath, S. P.; Zhao, F. J. Rapid reduction of arsenate in the medium mediated by plant roots. New Phytol. 2007, 176 (3), 590-599.

(31) Li, R. Y.; Ago, Y.; Liu, W. J.; Mitani, N.; Feldmann, J.; McGrath, S. P.; Ma, J. F.; Zhao, F. J. The rice aquaporin Lsil mediates uptake of methylated arsenic species. Plant Physiol. 2009, 150 (4), 2071-2080.

(32) Gong, Z.; Lu, X.; Cullen, W. R.; Le, X. C. Unstable trivalent arsenic metabolites, monomethylarsonous acid and dimethylarsinous acid. J. Anal. At. Spectrom. 2001, 16 (12), 1409-1413.

(33) Meng, X. Y.; Qin, J.; Wang, L. H.; Duan, G. L.; Sun, G. X.; Wu, H. L.; Chu, C. C.; Ling, H. Q.; Rosen, B. P.; Zhu, Y. G. Arsenic biotransformation and volatilization in transgenic rice. New Phytol. 2011, 191, 49-56.

(34) Yin, X. X.; Chen, J.; Qin, J.; Sun, G. X.; Rosen, B.; Zhu, Y. G. Biotransformation and volatilization of arsenic by three photosynthetic cyanobacteria. Plant Physiol. 2011, 156 (3), 1631-1638.

(35) Huang, H.; Jia, Y.; Sun, G. X.; Zhu, Y. G. Arsenic speciation and volatilization from flooded paddy soils amended with different organic matters. Environ. Sci. Technol. 2012, 46, 2163-2168.

(36) Taylor, G. J.; Crowder, A. Use of the DCB technique for extraction of hydrous iron oxides from roots of wetland plants. Am. J. Bot. 1983, 70 (8), 1254-1257.

(37) Liu, W. J.; Zhu, Y. G.; Smith, F. A.; Smith, S. Do iron plaque and genotypes affect arsenate uptake and translocation by rice seedlings (Oryza sativa L.) grown in solution culture? J. Exp. Bot. 2004, 55 (403), 1707-1713.

(38) Mestrot, A.; Uroic, M. K.; Plantevin, T.; Islam, M. R.; Krupp, E. M.; Feldmann, J.; Meharg, A. A. Quantitative and qualitative trapping of arsines deployed to assess loss of volatile arsenic from paddy soil. Environ. Sci. Technol. 2009, 43 (21), 8270-8275.

(39) Sun, G. X.; Williams, P. N.; Carey, A. M.; Zhu, Y. G.; Deacon, C.; Raab, A.; Feldmann, J.; Islam, R. M.; Meharg, A. A. Inorganic arsenic in rice bran and its products are an order of magnitude higher than in bulk grain. Environ. Sci. Technol. 2008, 42 (19), 7542-7546.

(40) Mihucz, V. G.; Tatár, E.; Virág, I.; Cseh, E.; Fodor, F.; Záray, G. Arsenic speciation in xylem sap of cucumber (Cucumis sativus L.). Anal. Bioanal. Chem. 2005, 383 (3), 461-466.

(41) Xu, X. Y.; McGrath, S. P.; Zhao, F. J. Rapid reduction of arsenate in the medium mediated by plant roots. New Phytol. 2007, 176 (3), 590-599.

(42) Quaghebeur, M.; Rengel, Z. The distribution of arsenate and arsenite in shoots and roots of Holcus lanatus is influenced by arsenic tolerance and arsenate and phosphate supply. Plant Physiol. 2003, 132 (3), 1600-1609.

(43) Abbas, M. H. H.; Meharg, A. A. Arsenate, arsenite and dimethyl arsinic acid (DMA) uptake and tolerance in maize (Zea mays L.). Plant Soil. 2008, 304, 277-289.

(44) Raab, A.; Williams, P. N.; Meharg, A. A.; Feldmann, J. Uptake and translocation of inorganic and methylated arsenic species by plants. Environ. Chem. 2007, 4, 197-203.

(45) Mestrot, A.; Feldmann, J.; Krupp, E. M.; Hossain, M. S.; Roman-Ross, G.; Meharg, A. A. Field fluxes and speciation of arsines emanating from soils. Environ. Sci. Technol. 2011, 45 (5), 1798-1804.

(46) Cheng, C. N.; Focht, D. D. Production of arsine and methylarsines in soil and in culture. Appl. Environ. Microb. 1979, 38, 494-498. 